\title{
THE EFFECT OF QUALITY OF ALUMINUM CASTS ON THEIR MECHANICAL PROPERTIES
}

\author{
Kateřina KREISLOVÁ, Libor TUREK \\ SVUOM Ltd., Prague, Czech Republic, EU, kreislova@svuom.cz, turek@svuom.cz
}

https://doi.org/10.37904/metal.2021.4216

\begin{abstract}
Material fatigue occurred on aluminum castings used in the electrical distribution network. Material analysis was performed on the damaged samples. The detailed analysis of fracture surface was performed by several methods. The decrease in mechanical properties was caused by the poor chemical composition of the alloy and defects caused by casting.
\end{abstract}

Keywords: Aluminum alloy cast, mechanical properties, fracture, matrix structure, impurities

\section{INTRODUCTION}

Worldwide demand for aluminum is around 29 million tons per year. Light structural materials and Al alloys in particular are widely used in the different industries owing to their high specific strength [1]. Further benefits of Al alloys relate to their relative advantage in terms of ductility, heat transfer, electrical conductivity, and corrosion resistance in regular atmospheric conditions. The aluminum cast AISi10Mg is used for numerous small sections in the electrical power distribution. During the last few years, the fatigue of some of them occurred for the newly installed ones. In this case study the 3 different aluminum alloys AISi10Mg cast parts of electrical distribution network installed on masts are evaluated after their failure.

There are various forms of impurities observed in molten aluminum with different compositions, sources, and morphology. These impurities have been examined and classified according to their size, chemical content, and phase. The incorporation of impurities in aluminum alloys can have a major effect on the properties of the material. In aluminum, the two most prominent types of impurities are oxide films (alumina or spinels) and intermetallic particles.

In aluminum alloys, it is general that fracture occurs from inclusions or second phases particles. Intergranular, local shear and delamination type fractures are also sometimes observed. The fatigue resistance of cast aluminum alloys is affected by microstructural defects, typically the largest porosity, and sometimes oxide films. Other microstructural factors which can affect fatigue life include secondary dendrite arm or cellular spacing, grain size, second-phase particles, intermetallic inclusions, and oxide inclusions (casting dross) [2]. The mechanical properties of cast products are not the same for different test orientations relative to the solidification directions. The qualitative effect of impurities on the mechanical properties of aluminum has been shown to be due to a number of factors [3]. Impurities disrupt an otherwise homogeneous stress field and, as a result of cumulative plastic deformation, at a threshold stress amplitude the microcracks will propagate. These microcracks form around the impurities because of a strong pile-up of dislocations. Since inclusions can nucleate secondary porosity more readily than grain boundaries can, they act as preferential sites for the nucleation, growth and coalescence of voids. The inclusions can debone from the matrix and crack independently of the matrix.

\section{ALUMINUM CAST PROPERTIES}

Aluminum is most commonly alloyed with copper, zinc, magnesium, silicon, manganese and lithium. Small 
additions of chromium, titanium, zirconium, lead, bismuth and nickel are also made and iron is invariably present in small quantities. Cast aluminum contains larger percentages of alloying elements when compared to wrought aluminum. Cast aluminum also has a generally lower tensile strength than wrought aluminum due to the difficulty in eliminating casting defects.

Aluminum alloyAISi10Mg is a typical casting alloy with good casting properties and it's typically used for cast parts with thin walls and complex geometry. It offers good strength, hardness and dynamic properties and is therefore also used for parts subject to high loads. AlSi10Mgalloybelongstohypoeutectic aluminum alloys group. Due to good mechanical properties combined with low density, corrosion resistance and excellent castability it is widely used in industrial applications. Eutectic Al + Si phase present in this alloy may significantly affect its ductility and strength, but also makes this material difficult to machine. Low shrinkage and relatively low melting temperature is characteristic for AISi10Mg alloy. For those reasons this alloy is mainly used for casting. EN 1706Aluminum and aluminum alloys - Castings - Chemical composition and mechanical properties specifies the chemical composition limits for aluminum casting alloys and mechanical properties of separately cast test pieces for these alloys. This technical standard was revised in 2020 and the chemical composition limits of the alloy EN AC-43000 [EN AC-Al Si10Mg] were modified. One of the reasons for the limited ductility of aluminum die casting alloys is the presence of iron within the alloys.

Table 1 AlSi10Mg alloy mechanical properties

\begin{tabular}{|c|c|c|c|}
\hline UTS $\boldsymbol{R} \boldsymbol{m}(\mathrm{MPa}), \min$ & YS $\boldsymbol{R} \boldsymbol{p}_{\mathbf{0 . 2}}(\mathrm{MPa}), \min$ & Elongation A (\%) & Brinell hardness $\boldsymbol{H} \boldsymbol{B}, \boldsymbol{m i n}$ \\
\hline 220 & 180 & 7 & 75 \\
\hline
\end{tabular}

Table 2 AISi10Mg alloy chemical composition (wt\%)

\begin{tabular}{|c|c|c|c|c|c|c|c|}
\hline $\mathbf{S i}$ & $\mathbf{F e}$ & $\mathbf{C u}$ & $\mathbf{M n}$ & $\mathbf{M g}$ & $\mathbf{Z n}$ & $\mathbf{T i}$ & $\mathbf{A l}$ \\
\hline $9.0-11.0$ & $0.45-0.55$ & 0.1 & 0.45 & $0.20-0.45$ & 0.1 & 0.15 & rem. \\
\hline
\end{tabular}

These alloys are usually produced from secondary alloys and recycling processes. Many of their based alloys contain impurities, while the levels of impurities in the recycled ones are multiplied during recycling process. Alloying elements, such as magnesium (Mg) and silicon ( $\mathrm{Si}$ ) are deliberately added to $\mathrm{Al}$ alloys to enhance their mechanical properties. Apart from the intentionally added elements, impurities such as $\mathrm{Fe}, \mathrm{Cu}, \mathrm{Cr}, \mathrm{Mn}$ and transition metals are usually present. Although these impurities are at trace levels in the alloys, they form new phase components called intermetallic that significantly influence the properties of the microstructures. Quite often, these impurities are strong sites for crack initiation that serve as weak points for decohesion failure.

\section{EVALUATED PARTS}

In this case study the 3 different aluminum cast parts of electrical distribution network installed on masts are compared - Figure 1. All parts are machined after casting. The walls of parts have different thickness. The fractures occurred on thinner walls. There were also evaluated the reference parts for each failure ones for comparison chemical composition, structure and hardness, etc.

\subsection{Visual evaluation}

The fracture occurred on thinner wall of parts. The first evaluation was done on fracture areas by 3D optical microscope Keyence VHX-5000 with different magnification - Figure 2. On fracture areas the dark, black impurities are evident in various sizes. 

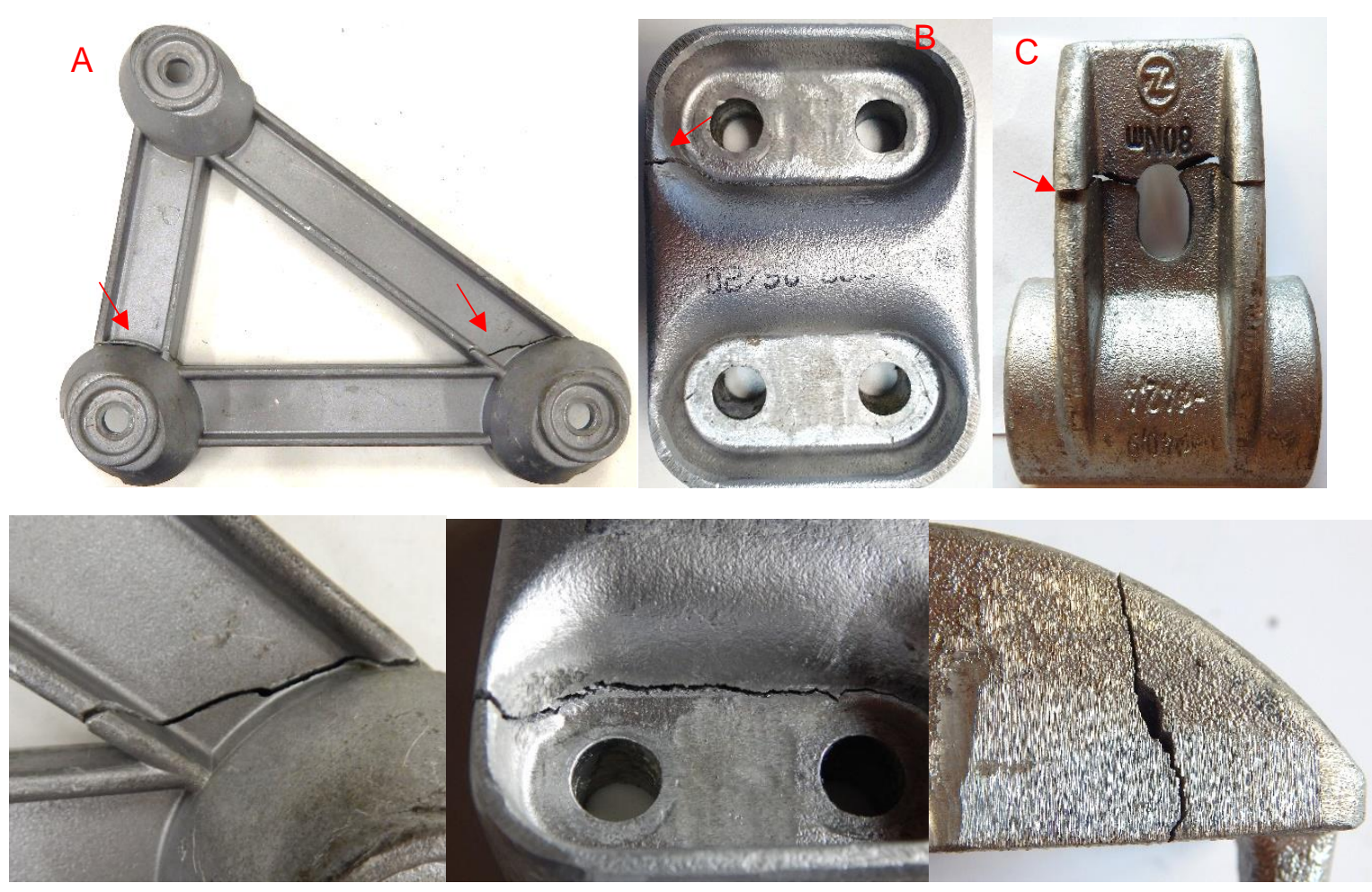

Figure 1 Parts with fractures and fractures details
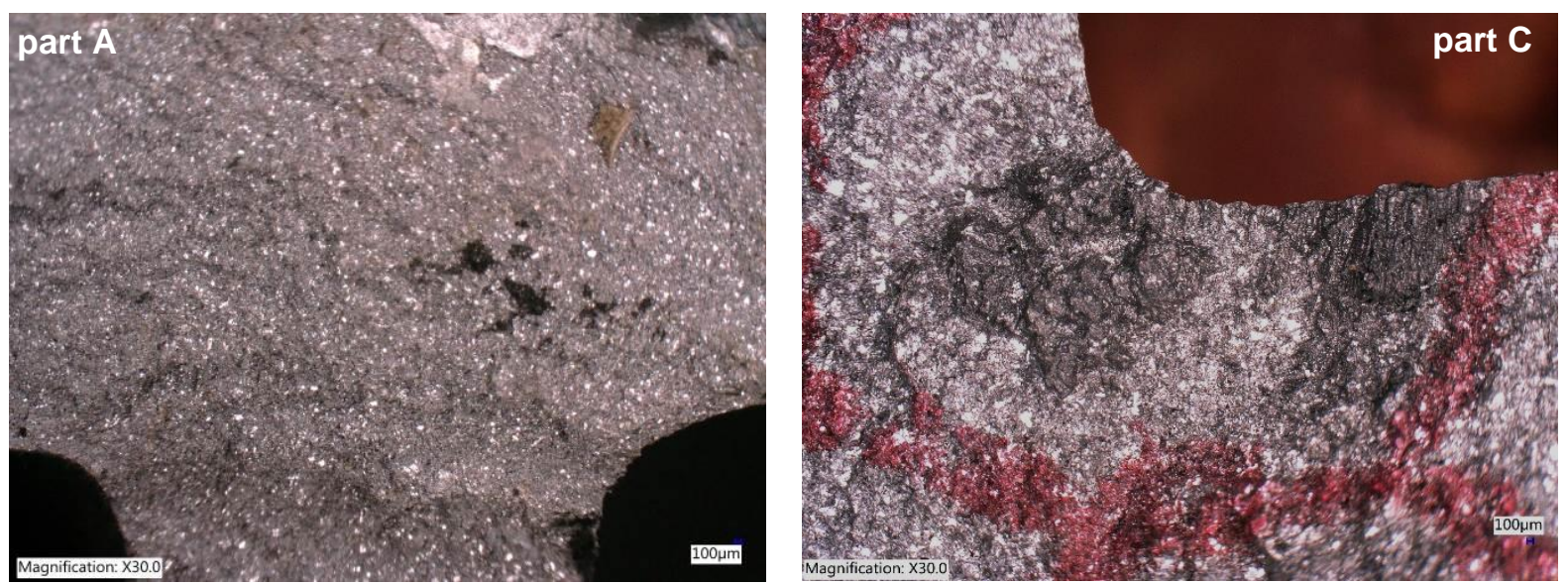

Figure 2 Fracture areas - examples of impurities

\subsection{Hardness measurement}

The hardness of aluminum casts was performed with tool RHL-110D, Huatec Group Corp., D type prove, a 3 $\mathrm{mm}$ diameter ball impression with an impact energy of $11 \mathrm{~mJ}$ according to EN 16859-1 Metallic materials Leeb hardness test - Part 1: Test method. The results are given in Table 3. It is evident that on failed parts the hardness of alloy material is lower (ca $42 \mathrm{HB}$ ) in comparison to reference ones (ca $58 \mathrm{HB}$ ).

Table 3 Hardness measurement of parts (HB)

\begin{tabular}{|c|c|c|c|}
\hline part & minimum & maximum & average \\
\hline reference part A, B, C & $40-56$ & $57-70$ & $57-62$ \\
\hline B, C failed part & $36-40$ & $55-56$ & $41-43$ \\
\hline
\end{tabular}




\subsection{SEM and EDX analysis of matrix}

Figure 3 shows the optical and SEM images of the alloys' microstructure from scanning electron microscopeTescan Vega II with an X-Max 50 SDD detector, Oxford Instruments. The SEM examinations of the fracture surfaces showed that the pores (shrinkages) and intermetallics were susceptible to fracture if their size was larger than several micrometres. The elementary analysis results are given in Table $\mathbf{4}$ for evaluated parts. The morphology of crack initiation pore on part Bfractured surfaceis shown on Figure 4. The example of elements' distribution is given on Figure $\mathbf{5}$ - along the crack the increased concentration of silicon Si and iron $\mathrm{Fe}$.
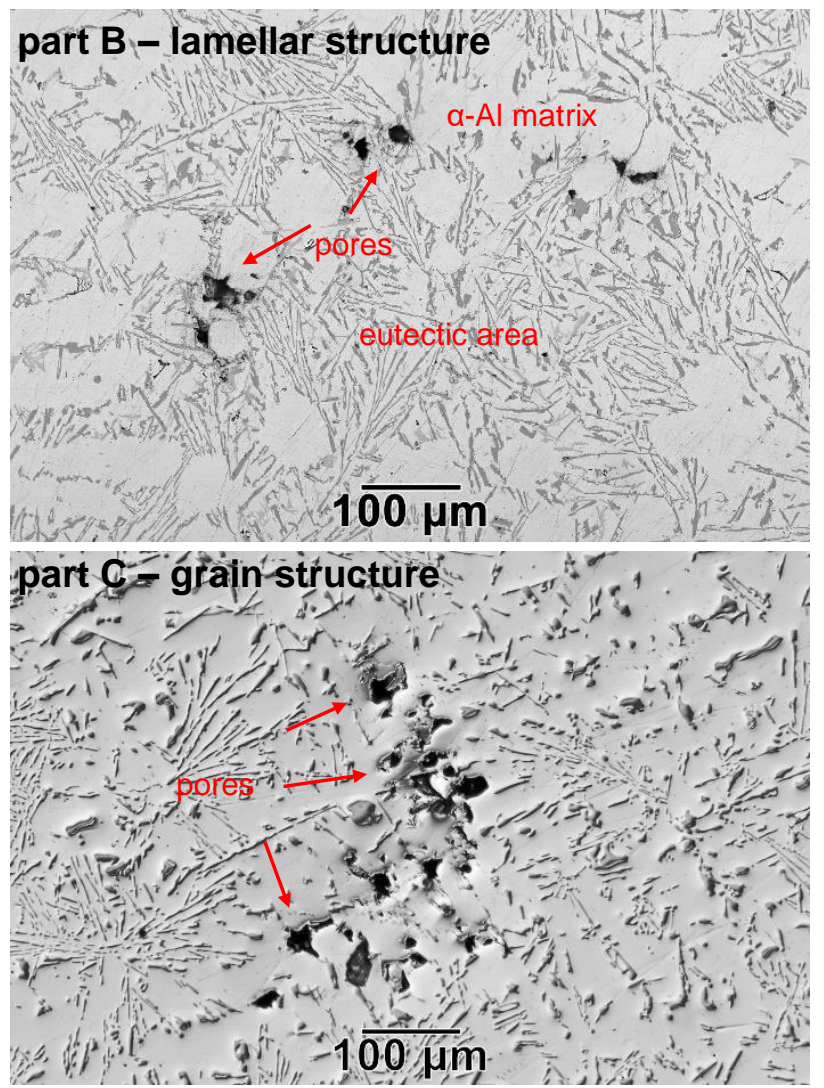

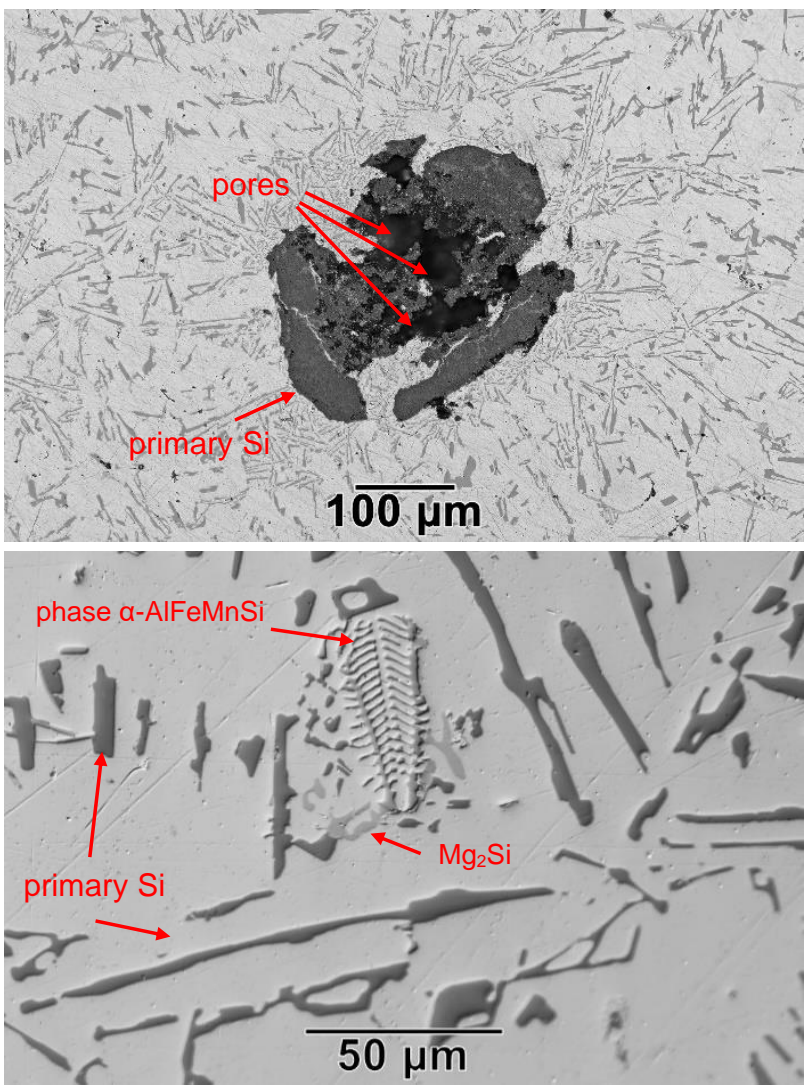

Figure 3 Structure of failed aluminum parts

Table 4 Elementary analysis of fractured surfaces of aluminum parts (wt\%) - typical areas

\begin{tabular}{|c|c|c|c|c|c|c|c|c|c|c|c|c|c|c|}
\hline part & area & $\mathbf{C}$ & $\mathbf{O}$ & $\mathbf{M g}$ & $\mathbf{A l}$ & $\mathbf{S i}$ & $\mathbf{S}$ & $\mathbf{C a}$ & $\mathbf{M n}$ & $\mathbf{M o}$ & $\mathbf{F e}$ & $\mathbf{C u}$ & $\mathbf{S n}$ & $\mathbf{P b}$ \\
\hline $\mathrm{A}$ & 1 & - & - & 0.03 & 61.64 & 8.62 & - & - & 5.13 & - & 21.42 & 2.28 & - & - \\
& 2 & - & - & 0.08 & 14.35 & 85.36 & - & - & - & - & 0.11 & 0.27 & - & - \\
& 3 & - & 3.62 & 18.46 & 62.56 & 14.60 & - & - & - & - & - & 0.35 & 1.10 & 1.14 \\
& 4 & - & - & 0.30 & 97.68 & 0.85 & - & - & 0.08 & - & - & 0.44 & - & - \\
\hline $\mathrm{B}$ & 1 & - & - & 1.19 & 56.24 & 16.77 & - & - & 0.41 & - & 25.60 & - & - & - \\
& 2 & - & - & 0.22 & 95.51 & 4.18 & - & - & 0.00 & - & 0.13 & - & - & - \\
& 3 & - & - & 0.47 & 52.29 & 47.35 & - & - & - & - & - & - & - & - \\
\hline C & 1 & 34.37 & 0.84 & - & 26.43 & 37.78 & 0.12 & 0.21 & - & 0.09 & 0.06 & - & - & - \\
& 2 & 73.99 & 7.48 & - & 2.45 & 1.17 & 2.61 & 7.78 & - & 3.33 & 0.02 & - & - & - \\
& 3 & 58.39 & 4.59 & - & 1.85 & 1.06 & 12.65 & 1.24 & - & 20.20 & - & - & - & - \\
\hline
\end{tabular}




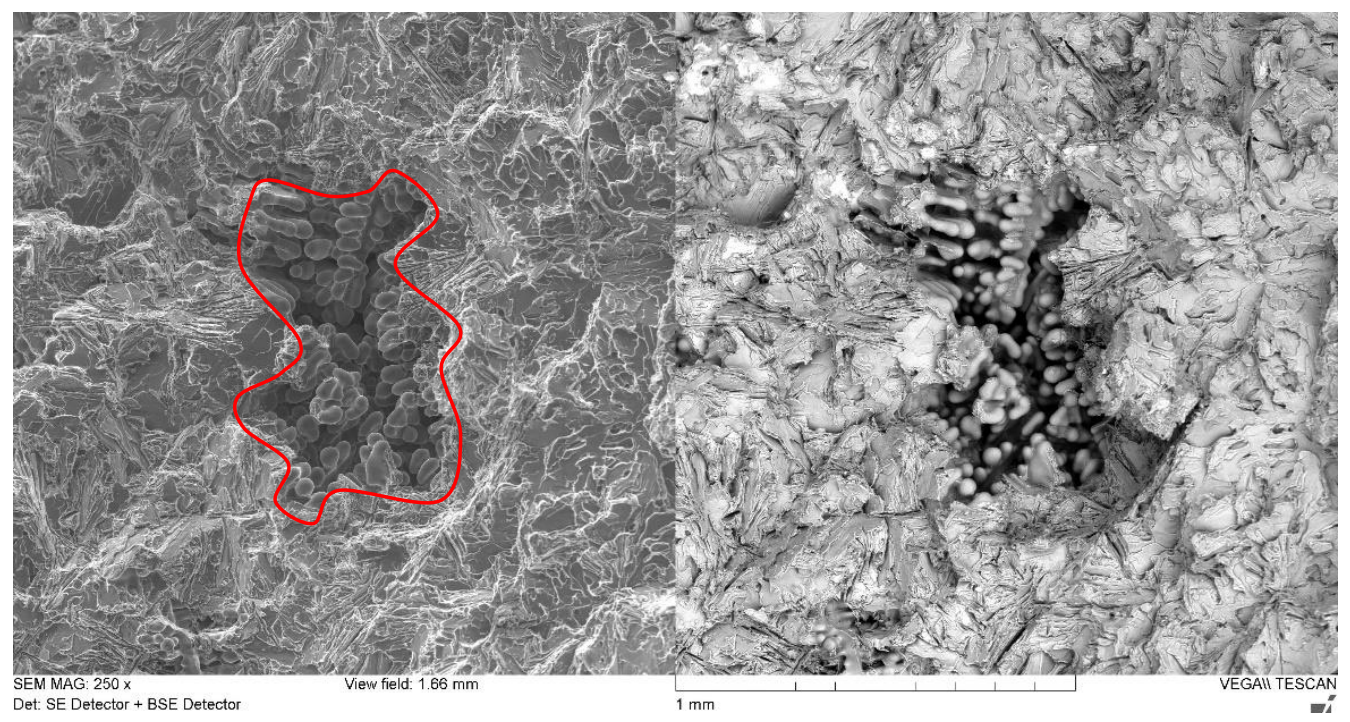

Figure 4 Part B -crack initiation pore
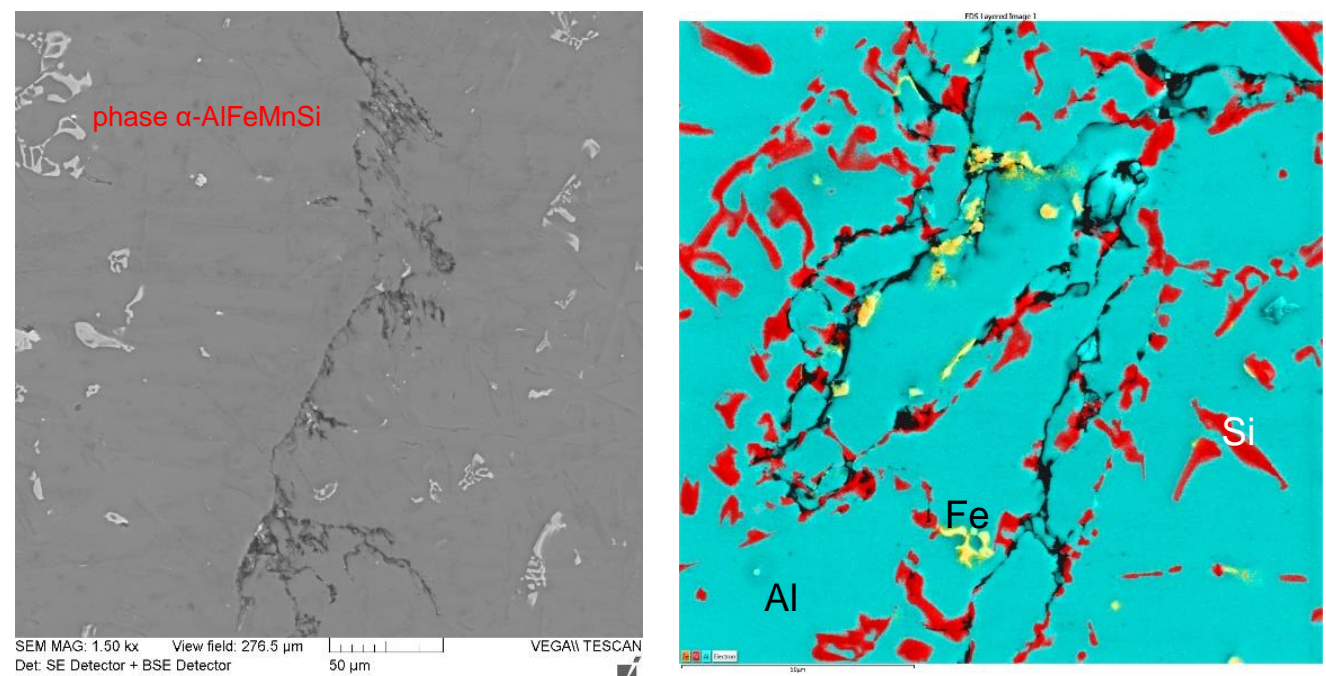

Figure 5 Part A - structure and elements' distribution along the crack

\section{DISCUSSION OF RESULTS}

Although these failed parts were produced by different producers and at different periods, they have the similar reason of fracture - poor microstructure of cast due to pores and inclusions in matrix. There are various forms of impurities observed in cast aluminum with different compositions, sources, and morphology. The identification of impurities was based on microstructure of alloys together with chemical analysis:

- Oxides are the most common impurity found in aluminum alloys. The oxide impurities reduce the ultimate tensile strength of materials. The oxide films act as initiation sites for fatigue cracks, and overall fatigue failure occurred considerably quicker than in relatively oxide-free aluminum castings.

- Aluminum carbides $\left(\mathrm{Al}_{4} \mathrm{C}_{3}\right)$ are most often seen in recycled aluminum alloys since the main source of carbon is the hydrocarbons present in lubricants. These carbide impurities are hard to remove because of their small size.

- The presence of silica $\left(\mathrm{SiO}_{2}\right)$ in aluminum alloys is due to the degradation or loss of ceramic refractory materials in the melt. Silica particles can agglomerate and are usually intertwined with $\mathrm{Al}_{2} \mathrm{O}_{3}$ and lime $(\mathrm{CaO})$ or other common refractory compounds. 
- The calcium impurities, such as $\mathrm{CaAl}_{4}, \mathrm{CaSi}_{2}$, and others, caused an increase in volumetric shrinkage, gas shrinkage porosity, and hydrogen solubility. The net effect was an increase in porosity during solidification and therefore, a reduction in the strength and ductility of the cast material.

\section{CONCLUSION}

Aluminum is one of the most commonly used materials in die casting. The pores occurrences and incorporation of impurities in aluminum alloys can have a major effect on the properties of the material. In aluminum, the two most prominent types of impurities are oxide films (alumina or spinel) and intermetallic particles. Scanning electron microscopy (SEM), energy dispersive spectroscopy (EDAX), conventional metallography and microhardness measurements were used to examine the effects of defects on fracture of cast parts. The following conclusions can be drawn from the failed case studies:

- $\quad$ surface or near surface pores reduce the time to crack initiation - large pores (gas pores) increase the crack propagation rate compared to the effect of small multiple pores (shrinkage porosity) for similar average porosity values;

- $\quad$ the aluminum die castings obtained a lot of different impurities;

- $\quad$ oxides trapped in the aluminum act as stress risers and cause the ultimate tensile, yield, and fatigue strengths of the material to decline dramatically. The overall result is premature failure of the aluminum component. The presence of oxides also reduces the corrosion resistance of pure aluminum;

- $\quad$ other impurities found in aluminum include magnesium silicate, aluminum carbide.

\section{ACKNOWLEDGEMENTS}

The study was performed and paper was written with support of project MPO - IP DKRVO, 2021.

\section{REFERENCES}

[1] SANTOS, M.C. jr., MACHADO, A.R., SALES, W.F., BARROZO, M.A.S., EZUGWU, M.O. Machining of aluminum alloys: A review. Int. J. Adv. Manuf. Technol. [online]. 2016, iss. 9-12, p. 15. Available from: https://doi.org/10.1007/s00170-016-8431-9.

[2] TANG, M., Inclusions, porosity, and fatigue of AISi10Mg parts produced by Selective Laser Melting. Pittsburgh: Carnegie Mellon University, 2017.

[3] BELL, S., DAVIS, B., JAVAID, A., ESSADIQI, E., Final report on effect of impurities in aluminum. Report No. 2003-20(CF). [online]. 2006. Available from: https://www.researchgate.net/publication/306292737. 